\title{
Determination of Polyphenols in White Wines by Liquid Chromatography: Application to the Characterization of Alella (Catalonia, Spain) Wines Using Chemometric Methods
}

\author{
Alexander Larrauri \\ University of Barcelona, Department of Analytical Chemistry, Martí i Franquès 1-11, E-08028, Barcelona, Spain \\ OSCAR NúÑEZ \\ University of Barcelona, Department of Analytical Chemistry, Martí i Franquès 1-11, E-08028, Barcelona, Spain; University of \\ Barcelona, Research Institute in Food Nutrition and Food Safety, Recinte Torribera, Av Prat de la Riba 171, Edifici de Recerca \\ (Gaudí), Santa Coloma de Gramenet, E-08921 Barcelona, Spain; and Generalitat de Catalunya, Serra Hunter Fellow, Barcelona, \\ Spain \\ Santiago Hernández-Cassou and JaVier Saurina ${ }^{1}$ \\ University of Barcelona, Department of Analytical Chemistry, Martí i Franquès 1-11, E-08028, Barcelona, Spain; University of \\ Barcelona, Research Institute in Food Nutrition and Food Safety, Recinte Torribera, Av Prat de la Riba 171, Edifici de Recerca \\ (Gaudí), Santa Coloma de Gramenet, E-08921 Barcelona, Spain
}

The determination of polyphenols in wines is of great interest in the field of food analysis due to health and organoleptic implications. In addition, the applicability of polyphenols as food descriptors to be used for characterization, classification, and authentication purposes is gaining popularity. In this work, a simple and reliable method based on HPLC separation in reversed-phase mode with UV-Vis detection was developed and applied to determine polyphenolic compounds in white wines. The chromatographic separation was performed using a C18 column under a methanol elution gradient and assessed by an experimental design approach. Analytical parameters were established under the optimal experimental conditions. LOD values were between 3 and $220 \mu \mathrm{g} / \mathrm{L}$, and repeatability values were better than $1 \%$ for most of the analyzed polyphenols. Compositional data were further exploited to characterize white wines based on principal component analysis to discriminate among mono- and polyvarietal compositions.

$\mathrm{P}$ olyphenols are secondary metabolites of plants that display important physiological roles, e.g., in the growth and reproduction of plants, in resistance to microorganism and insect attacks, and in the protection against environmental stressors such as UV radiation and high temperatures $(1,2)$. Polyphenols are commonly classified according to their chemical structures, which depend on the number of phenolic rings and their structural links (3). The main polyphenolic

Guest edited as a special report on "Application of Multivariate Statistical Techniques in Chromatographic and Spectroscopic Fingerprinting of Complex Food and Environmental Samples" by Paweł K. Zarzycki.

${ }^{1}$ Corresponding author's e-mail address: xavi.saurina@ub.edu

This work was partially financed by the Generalitat de Catalunya and the Spanish Ministerio de Economía y Competitividad with projects NASSOS 2014SGR377 and Superfactory CTQ2014-56324.

DOI: 10.5740/jaoacint.16-0407 groups are phenolic acids and flavonoids, accounting for around 30 and $70 \%$ of dietary polyphenols, respectively (4-6). Some relevant phenolic acids in white wines include hydroxybenzoic derivatives (e.g., ethyl gallate and gallic, homogentisic, protocatechuic, gentisic, vanillic, and syringic acids) and hydroxycinnamic acids and related compounds (e.g., caftaric, caffeic, $p$-coumaric, and ferulic acids). Flavonoids share a common structure based on a diphenyl pyran skeleton (C6-C3-C6). Flavonoid subgroups differ in the connection of the aromatic ring to the condensed heterocyclic ring, as well as in the oxidation state and functional groups of the heterocyclic ring (3). Among others, the most abundant flavonoids in white wines are flavones (e.g., apigenin), flavonols (myricetin, quercetin, kaempferol, and rutin), and flavanols (catechin and epicatechin).

The interest in the determination of polyphenols in food products and, in particular, in wines is increasing due to their health and organoleptic implications (7-9). Several beneficial effects attributed to this family of compounds have been well documented, including cardioprotective, anti-inflammatory, antioxidant, and antibacterial activities (10-16). In addition, polyphenols strongly influence some sensorial attributes such as color and astringency. Recently, the role of polyphenols as food descriptors to be used for characterization, classification, and authentication purposes has stirred up great analytical possibilities (17). The variety and concentrations of chemical constituents of wines depend on several factors such as geographic origin, grape varieties, winemaking practices, etc. (18).

The polyphenol content in white wines is, in general, 1 order of magnitude lower than that occurring in red wine counterparts due to differences in winemaking practices (19-22). In particular, polyphenols are mainly extracted from grape skin and seeds during maceration and fermentation processes, which are typical steps in the elaboration of red wines. In the case of white wines, however, the contact of the polyphenol sources with the must is limited, so their concentrations in the final products are significantly lower.

As mentioned above, polyphenolic profiles have been exploited to carry out wine characterization and classification 
based on chemometric methods for data analysis. In particular, principal component analysis (PCA) has been used for exploratory studies of wine characterization according to geographical origin, grape varieties, and vintages (22-27). In some cases, classification models have been assessed by partial least-squares (PLS) regression, PLS discriminant analysis, and soft independent modeling of class analogy in order to assign unknown samples to preestablished classes $(25,27)$.

This work aims at developing an appropriate analytical method based on HPLC with UV detection [diode-array detector (DAD)] for a fast determination of polyphenols in white wines. HPLC-DAD was chosen as a simpler and less-expensive technique than other, more powerful platforms such as those relying on LC with MS detection. In addition, our method provides significant time savings in comparison to other existing HPLC-UV methods, with chromatographic runs taking $40 \mathrm{~min}$. Despite some analyte identification and resolution issues, the proposed method may be very satisfactory for rapid analysis of large sets of samples. The chromatographic separation was established using selected polyphenols that are understood to be the most abundant in white wines. After the method optimization, figures of merit were established, including repeatability, LOD, sensitivity, linearity, and accuracy. The method was applied to the determination of polyphenols in monovarietal or polyvarietal white wine samples. Compositional profiles were exploited as a source of chemical information to be treated by PCA.

\section{Experimental}

\section{Chemicals and Standards}

Unless specified, analytical grade reagents were used. The mobile phase was prepared with Milli-Q water (Millipore, Milford, MA), formic acid [99\% (w/w), Sigma-Aldrich, St. Louis, MO), and methanol (MeOH; Ultra-HPLC Supergradient; PanReac AppliChem, Barcelona, Spain). Polyphenols, including gallic, homogentisic, protocatechuic, caftaric, gentisic, vanillic, caffeic, syringic, ferulic, and coumaric acids, and (+)-catechin, (-)-epicatechin, ethyl gallate, resveratrol, rutin, myricetin, quercetin, kaempferol, and apigenin, were purchased from Sigma-Aldrich. Stock standard solutions of each polyphenol were prepared in $\mathrm{MeOH}$ at a concentration of $1 \mathrm{mg} / \mathrm{mL}$.

\section{Samples}

White wines were kindly provided by Alella Vinicola S.A. (Alella, Barcelona, Spain). The sample set consisted of 11 wines of the protected designation of origin (PDO) Alella (five mono- and six polyvarietal) and one wine of the PDO Penedès. Monovarietal wines were elaborated from Pansa Blanca grapes (known as Xarel.lo in Penedès), and the polyvarietal counterparts were elaborated from Pansa Blanca plus Garnacha Blanca. In addition, a QC sample consisting of a mixture of $100 \mu \mathrm{L}$ of each wine sample was prepared to evaluate the repeatability of the method and the robustness of the chemometric results.

Wine samples were designated as follows: S1, Serralada de Marina Pansa Blanca (Alella); S2, Pansa Blanca Organic Wine 2014 (Alella); S3, Pansa Blanca 2014 (Alella); S4, Young Pansa y Garnacha 2014 (Alella); S5, Celler Pardas Xarel.lo (Penedés); S6, Bouquet d'a 2014 (Alella); S7, SO de Masia Can Roda Pansa Blanca 2014 (Alella); S8, IN VITA 2014 (Alella); S9,
Ivori Vi Blanc de Cupatge 2012 (Alella); S10, Ivori Vi Blanc Pansa Blanca Garnatxa Blanca (Alella); S11, Marfil Vi Blanc Classic Pansa Blanca Garnatxa Blanca (Alella); and S12, Marfil Vi Blanc Sec Pansa Blanca (Alella).

\section{LC Method}

The chromatograph consisted of an Agilent 1100 Series HPLC instrument equipped with a quaternary pump (G1311A), a degasser (G1379A), an autosampler (G1392A), a DAD (G1315B), and a personal computer with the Agilent ChemStation software (Rev. A 10.02), all from Agilent Technologies (Waldbronn, Germany). The separation column was a Kinetex C18 $(100 \times 4.6 \mathrm{~mm}$ id, particle size $2.6 \mu \mathrm{m})$ furnished with a SecurityGuard C18 cartridge (both from Phenomenex, Torrance, CA). The separation was based on the following gradient using $0.1 \%(\mathrm{v} / \mathrm{v})$ formic acid aqueous solution and $\mathrm{MeOH}$ as the components of the mobile phase: 0 to $33 \mathrm{~min}, 3 \% \rightarrow 65 \% \mathrm{MeOH}$; 33 to $34 \mathrm{~min}, 65 \% \rightarrow 90 \% \mathrm{MeOH}$; 34 to $37 \mathrm{~min}, 90 \% \mathrm{MeOH}$; 37 to $37.1 \mathrm{~min}, 90 \% \rightarrow 3 \% \mathrm{MeOH}$; and 37.1 to $40 \mathrm{~min}, 3 \% \mathrm{MeOH}$. The flow rate was $1 \mathrm{~mL} / \mathrm{min}$ and the injection volume was $10 \mu \mathrm{L}$. Chromatograms were recorded at 280, 310, and $370 \mathrm{~nm}$, the sensitive wavelengths of phenolic, cinnamic, and flavonoid compounds, respectively.

\section{Data Analysis}

SOLO from Eigenvector Research was used for PCA calculations (28). A detailed description of the theoretical background of these methods is given elsewhere (29).

The data consisted of polyphenol concentrations from a set of white wines analyzed in triplicate. Data were autoscaled before PCA to provide similar weights to all variables (i.e., compounds) under study. PCA results consisted of plots of scores and loadings that show the distribution of the samples and variables on the principal components (PCs), respectively. The study of scores was used to infer patterns of sample characteristics, such as winemaking style or grape varieties. The plot of loadings displayed the distribution of variables to gain information about their correlations.

\section{Results and Discussion}

\section{Optimization of the Chromatographic Conditions}

The optimization of the chromatographic method focused on assessing the experimental conditions leading to the most suitable separation on the basis of maximum resolution of analytes and minimum analysis time. For such a purpose, multicriteria decision functions were defined as the way to reach an appropriate compromise among the desired objectives. Similar decision strategies have been applied elsewhere for dealing with other complex chromatographic separations (30, 31). Separation conditions were preliminarily assayed using standard solutions of polyphenols (at $5 \mathrm{mg} / \mathrm{L}$ each) selected from results previously published regarding the most abundant polyphenols in German, South African, Chinese, and Spanish white wines from Chardonnay, Sauvignon Blanc, Riesling, and other grape cultivars (19-22). Although their compositions may differ from Pansa Blanca and Garnacha Blanca wines, they 
could reasonably be used as a starting point to establish the composition of these wines.

Preliminary elution studies showed that a $\mathrm{MeOH}$ percentage of $3 \%$ was required to separate the most polar analytes (e.g., gallic acid) from the dead volume peak. For the less-polar compounds, $\mathrm{MeOH}$ percentages of $50 \%$ allowed their elution in a short time. Hence, linear gradient profiles were applied in which the $\mathrm{MeOH}$ percentage increased from 3 to $50 \%$ at different elution times $(15,20,25,30,40$, and $60 \mathrm{~min})$. After the separation step, the $\mathrm{MeOH}$ content was raised to $90 \%$ as a preventive measure to clean the column and avoid any residue of compounds that might remain in the column.

The separation quality of these runs was evaluated in terms of number of resolved compounds and retention time of the last peak of standards (apigenin) as a compromise between resolution and analysis time. The mathematical function to express the suitability of the separation was based on a Derringer desirability function, defined as $\left(d_{p} \times d_{t R}\right)^{1 / 2}$, where $d_{p}=$ the desirability of the number of peaks; and $d_{t R}=$ the desirability of the retention time of apigenin $\left(t_{\mathrm{R} \text { apigenin }}\right)$. For $t_{\mathrm{R} \text { apigenin }}$, limits of optimal $(d=1)$ and unacceptable $(d=0)$ conditions were fixed at 10 and $40 \mathrm{~min}$, respectively. In the case of the number of peaks, all the analytes (19 compounds) should be resolved. The desirability results indicated that the best separation was obtained with a gradient time of $30 \mathrm{~min}$. Under these conditions, however, peaks of some of the polyphenols (quercetin, kaempferol, and apigenin) were eluted within the cleaning step, so finer readjustments were done to improve the separation of these compounds to avoid such a washing range. Hence, the separation gradient profile finally chosen consisted of a linear increase in the $\mathrm{MeOH}$ percentage from 3 to $65 \%$ in $33 \mathrm{~min}$, together with a further $\mathrm{MeOH}$ increase from 65 to $90 \%$. In this way, all the analytes of the standard mixture were fully separated under the selected gradient (see Figure 1a).

The performance of the separation gradient was also assessed under similar experimental conditions using the QC mixture as a wine model. The criterion for the separation quality was analogous to that expressed in the case of pure standards. As shown in Figure 1b, various additional peaks of unknown components were encountered, but because the peaks of the analytes were well separated from those of the unknowns, the impact of potential interferences was negligible. According to spectral and polarity properties of the unknown compounds, those with a retention time in the range of 2-10 min might correspond to other hydroxybenzoic and hydroxycinnamic species; in addition, minor peaks at retention times higher than $10 \mathrm{~min}$ were attributable to flavonoids.

\section{Validation of the Method}

Aqueous standard solutions to be used for the assessment of the figures of merit were prepared in water from a proper dilution of the corresponding stock solutions. The linearity of the proposed method was evaluated in the concentration range of $0.05-50 \mathrm{mg} / \mathrm{L}$. In particular, polyphenol standards at 0.05 , $0.1,0.2,0.5,1,2,5,10,20$, and $50 \mathrm{mg} / \mathrm{L}$ were analyzed with
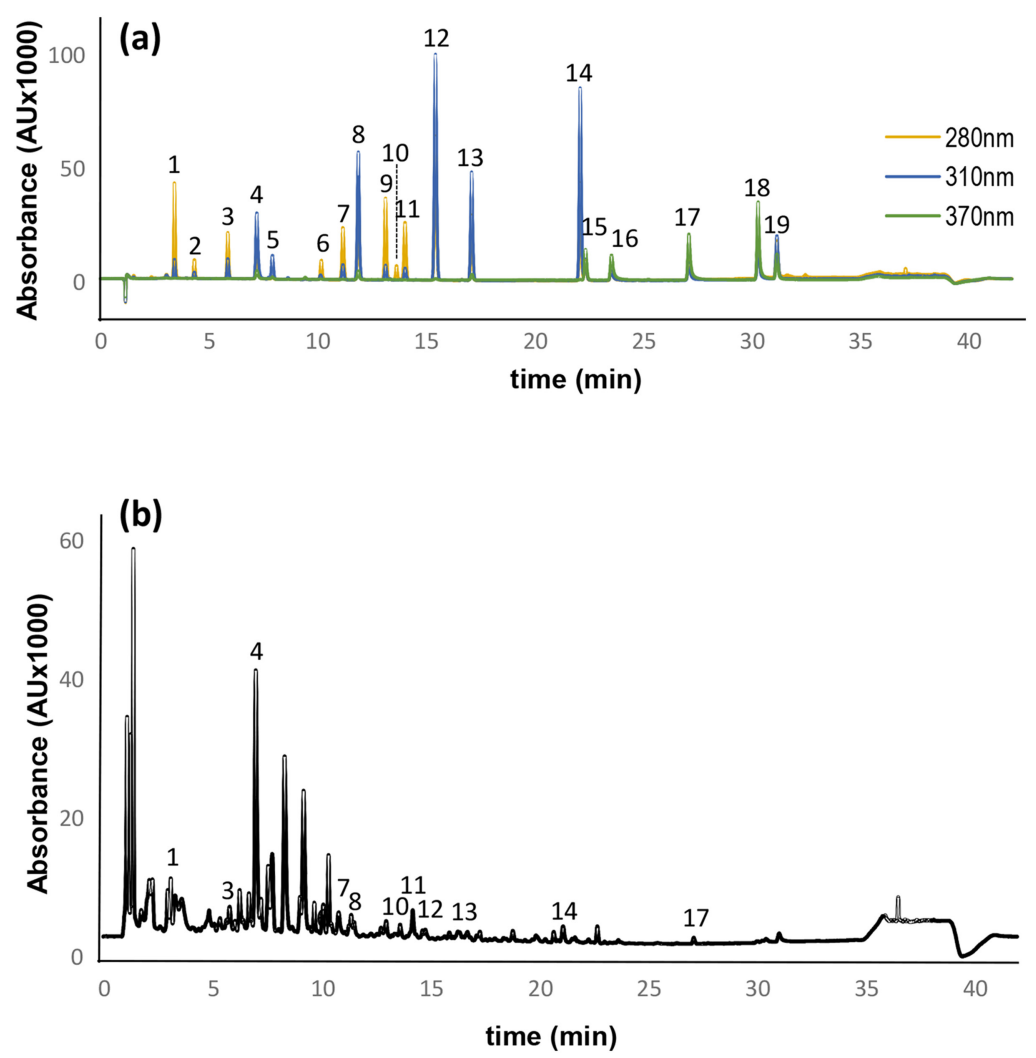

Figure 1. Chromatogram under optimal conditions of (a) a standard solution of 19 polyphenols at $5 \mathrm{mg} / \mathrm{L}$ and (b) a white wine QC sample. Peak assignation: 1, gallic acid; 2, homogentisic acid; 3, protocatechuic acid; 4, caftaric acid; 5, gentisic acid; 6, catechin; 7, vanillic acid; 8, caffeic acid; 9, syringic acid; 10, ethyl gallate; 11 , (-)-epicatechin; 12, p-coumaric acid; 13, ferulic acid; 14, resveratrol; 15, rutin; 16, myricetin; 17 , quercetin; 18, kaempferol; and 19, apigenin. 
the HPLC-DAD method (for caftaric acid, concentrations ranged from 0.1 to $100 \mathrm{mg} / \mathrm{L}$ ). Linear relationships between peak areas and analyte concentrations were established by means of least-squares regression at the optimal wavelength for each compound, i.e., $280 \mathrm{~nm}$ for hydroxybenzoic acids, $310 \mathrm{~nm}$ for hydroxycinnamic acids and stilbenes, and $370 \mathrm{~nm}$ for flavonoids.

Table 1 shows the retention times, slopes, and the regression coefficients obtained in the calibration curves of each compound. It can be seen that the highest sensitivities were attained for stilbenes (resveratrol) and hydroxycinnamic acids (e.g., $p$-coumaric and ferulic acids), whereas the lowest sensitivities were obtained for some benzoic acids (e.g., gentisic and homogentisic acids) and catechins. The linearity in all the cases was excellent, with correlation coefficients typically equaling 0.9999 (better than 0.997 all the cases).

The precision of the method was estimated from six replicate analyses of a standard mixture that included $5 \mathrm{mg} / \mathrm{L}$ concentrations each compound. Intraday repeatability values of retention time and peak area, expressed as SD and RSD, were calculated. Results given in Table 1 indicate that the variability in the retention time was excellent, with RSD values below $1 \%$ (with the exception of gallic acid). Regarding peak areas, most of the RSD values were below $1 \%$.

LODs were estimated at an S/N of 3 as follows: $3 \times \mathrm{SD}^{-1}$, where $\mathrm{SD}=$ the $\mathrm{SD}$ of the lowest concentration standard; and $s=$ the sensitivity (slope) of the corresponding calibration curve. As shown in Table 1, LODs ranged between 3 and $220 \mu \mathrm{g} / \mathrm{L}$, depending on the compound.

The repeatability in terms of concentration was also assessed in white wine matrixes using the QC mixture as a representative sample. The QC was injected six times, and results corresponding to the detected compounds are given in
Table 2. It can be seen that RSD values for most of the analytes were below $5 \%$, thus indicating that the repeatability of the method was highly satisfactory.

\section{Determination of Polyphenols in White Wines}

The proposed method was applied to the determination of polyphenols in white wines of Pansa Blanca and Garnacha Blanca varieties, as detailed in the Experimental section. Polyphenol standards in the concentration range of $0.1-50 \mathrm{mg} / \mathrm{L}$ were run for calibration purposes (up to $100 \mathrm{mg} / \mathrm{L}$ for caftaric acid). Wines were analyzed in triplicate. Each independent replicate was injected randomly. A QC (see above) and a standard at $5 \mathrm{mg} / \mathrm{L}$ were inserted every 10 wine injections in order to control the method performance (repeatability, sensitivity, and chromatographic resolution) within the series of runs.

Overall results showed that caftaric acid was the most abundant compound, occurring at a concentration of approximately $30 \mathrm{mg} / \mathrm{L}$. Other components, such as catechin and gallic acid, were found at approximately $5 \mathrm{mg} / \mathrm{L}$. Mean concentrations of vanillic and caffeic acids and ethyl gallate occurred at concentrations of around $2 \mathrm{mg} / \mathrm{L}$. The rest of the polyphenols were present, in general, at levels below $1 \mathrm{mg} / \mathrm{L}$.

For a more detailed comparison of the polyphenolic content of the Pansa Blanca and the Pansa Blanca plus Garnacha Blanca classes, Figure 2 shows the corresponding box-and-whisker plots. From these results, it was concluded that monovarietal Pansa Blanca wines had a lower overall analyte content, whereas wines with Pansa Blanca plus Garnacha Blanca varieties were richer in polyphenols. For instance, the mean concentration of caftaric acid was more than twice as high in the polyvarietal wines than in the Pansa Blanca ones. Similar results were found

Table 1. Figures of merit of the proposed method

\begin{tabular}{|c|c|c|c|c|c|c|c|c|}
\hline Polyphenol & Wavelength, $\mathrm{nm}$ & $\begin{array}{l}\text { Retention } \\
\text { time, min }\end{array}$ & $\begin{array}{l}\text { Retention time } \\
\text { RSD, \% }\end{array}$ & $\begin{array}{c}\text { Working } \\
\text { range, mg/L }\end{array}$ & Slope & $\mathrm{R}^{2}$ & $\mathrm{LOD}, \mu \mathrm{g} / \mathrm{L}$ & $\begin{array}{c}\text { Peak area } \\
\text { RSD, \% }\end{array}$ \\
\hline Gallic acid & 280 & 3.20 & 1.10 & $0.05-50$ & 26.8 & 0.9999 & 13 & 0.48 \\
\hline Homogentisic acid & 280 & 4.04 & 0.93 & $0.2-50$ & 6.98 & 0.9999 & 59 & 0.60 \\
\hline Protocatechuic acid & 280 & 5.53 & 0.65 & $0.2-50$ & 15.4 & 0.9999 & 16 & 0.58 \\
\hline Caftaric acid & 310 & 6.78 & 0.78 & $0.2-100$ & 32.3 & 0.9999 & 11 & 0.50 \\
\hline Catechin & 310 & 9.49 & 0.42 & $0.2-50$ & 6.02 & 0.9999 & 66 & 0.69 \\
\hline Vanillic acid & 280 & 10.55 & 0.35 & $0.2-50$ & 17.4 & 0.9999 & 28 & 0.58 \\
\hline Caffeic acid & 310 & 11.18 & 0.39 & $0.5-50$ & 54.6 & 0.9999 & 218 & 0.66 \\
\hline Syringic acid & 280 & 12.37 & 0.28 & $0.05-50$ & 28.1 & 0.9999 & 14 & 0.63 \\
\hline Ethyl gallate & 280 & 12.76 & 0.31 & $0.2-50$ & 5.70 & 0.9999 & 58 & 0.68 \\
\hline$p$-Coumaric acid & 310 & 14.55 & 0.34 & $0.05-50$ & 79.0 & 0.9999 & 3.7 & 1.08 \\
\hline Ferulic acid & 310 & 16.11 & 0.20 & $0.05-50$ & 47.2 & 0.9999 & 8.7 & 0.87 \\
\hline Resveratrol & 310 & 20.78 & 0.23 & $0.05-50$ & 74.2 & 0.9999 & 3.3 & 0.65 \\
\hline Rutin & 370 & 20.97 & 0.22 & $0.2-50$ & 13.9 & 0.9999 & 48 & 1.57 \\
\hline Myricetin & 370 & 22.10 & 0.22 & $0.5-50$ & 25.3 & 0.9973 & 102 & 1.64 \\
\hline Quercetin & 370 & 25.50 & 0.17 & $0.2-50$ & 31.4 & 0.9974 & 69 & 1.94 \\
\hline Kaempferol & 370 & 28.47 & 0.16 & $0.1-50$ & 33.2 & 0.9992 & 26 & 2.01 \\
\hline Apigenin & 370 & 29.27 & 0.16 & $0.05-50$ & 28.3 & 0.9995 & 17 & 1.30 \\
\hline
\end{tabular}


Table 2. Evaluation of concentration repeatability ( $n=6$ ) on white wine matrixes using the QC mixture as a representative sample

\begin{tabular}{lcc}
\hline Polyphenol & Concentration, mg/L & Repeatability RSD, \% \\
\hline Gallic acid & 5.35 & 2.01 \\
Protocatechuic acid & 0.87 & 10.3 \\
Caftaric acid & 30.43 & 1.04 \\
Catechin & 3.94 & 4.09 \\
Vanillic acid & 1.82 & 1.79 \\
Caffeic acid & 2.61 & 0.68 \\
Ethyl gallate & 2.54 & 4.07 \\
Epicatechin & 0.72 & 5.03 \\
p-Coumaric acid & 0.92 & 0.42 \\
Ferulic acid & 0.59 & 1.65 \\
Resveratrol & 0.35 & 0.98 \\
Quercetin & 1.09 & 0.52 \\
\hline
\end{tabular}

for catechin and gallic and caffeic acids, whereas epicatechin seemed to be more abundant in some Pansa Blanca wines. These differences, however, could not be generalized (i.e., were not significant) due to the wide concentration ranges, making the extraction of reliable conclusions difficult. Hence, none of the analytes could be considered a characteristic marker of each class. Owing to the implicit limitations in the descriptive performance of comparisons based on concentrations, a more comprehensive chemometric approach was applied to try to take advantage of compositional profiles for discrimination and classification purposes.

\section{Characterization of Wines by PCA}

The compositional profiles of polyphenols were applied to tackle the characterization of wines by PCA. Data to be analyzed consisted of concentration values of polyphenols determined in the white wines, as well as in the replicates of the QC sample. Data were first autoscaled to equalize the contribution of all variables to the model.

PCA results indicated that $\mathrm{PC} 1$ and $\mathrm{PC} 2$ retained more than $50 \%$ of variance from this data set. The scatter plot of scores of PC1 versus PC2 reveals that the wines were distributed according to the type of grapes used for their elaboration (Figure 3a). It can be seen that monovarietal wines from Pansa Blanca are located on the left side, whereas wines combining Pansa Blanca and Garnacha Blanca are on the right. In addition, the QC replicates appear in a compact group in the center of the graph. Hence, PC1 clearly discriminated samples according to mono- and polyvarietal classes. The overall polyphenol amount was also reflected in PC1, because richer wines appeared on the right and those with lower concentrations were mainly on the

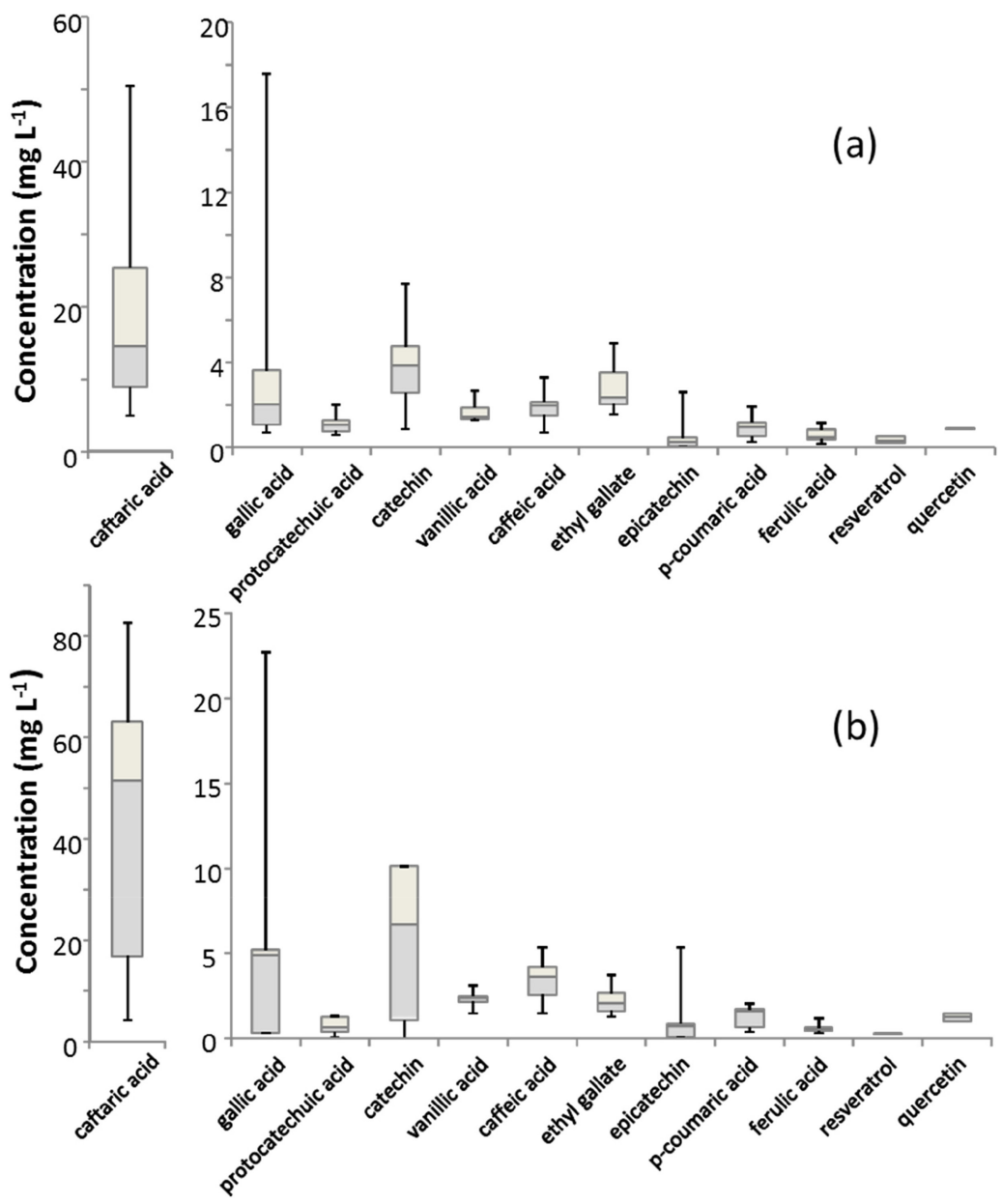

Figure 2. Box-and-whisker plots corresponding to the determination of polyphenols in white wines. (a) Pansa Blanca wines. (b) Pansa Blanca plus Garnacha Blanca wines. 
(a)

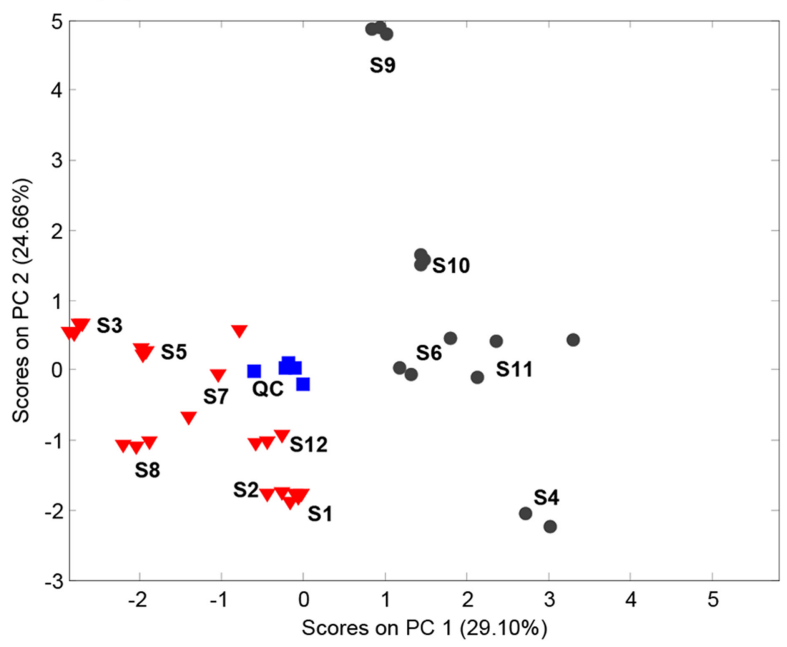

(b)

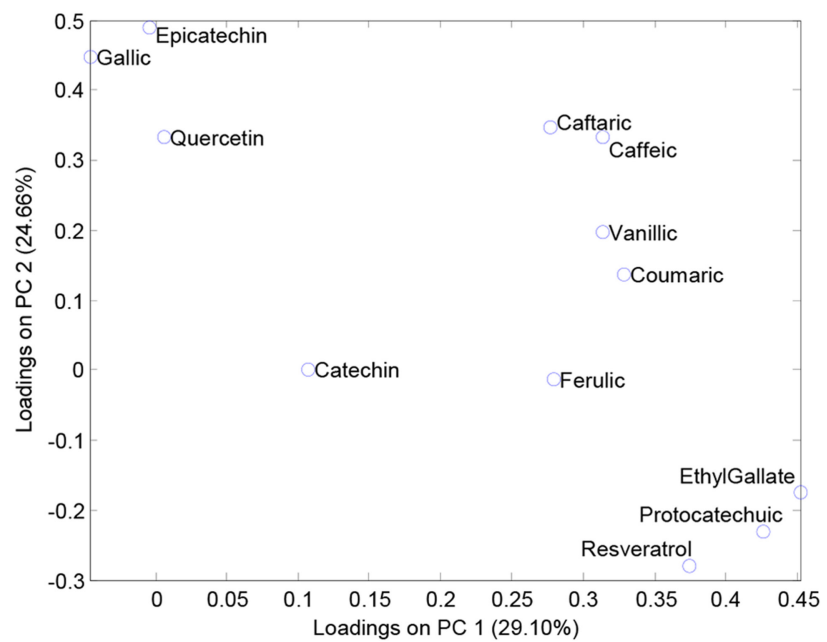

Figure 3. Characterization of wines by PCA. (a) Plot of scores. Sample assignation: triangles, monovarietal (Pansa Blanca); circles, polyvarietal (Pansa Blanca plus Garnacha Blanca); and squares, QC. (b) Plot of loadings.

left. PC2 seemed to be quite related to ageing, because the oldest wines predominated at the top and the youngest counterparts at the bottom.

The study of variables from the map of loadings showed some content correlations, such as gallic acid and epicatechin, and caffeic acid and related compounds (Figure $3 b$ ). It was deduced that caftaric and other hydroxycinnamic acids were especially abundant in polyvarietal wines. The rest of the polyphenols were also more abundant in the polyvarietal class, although the differences were not as marked.

\section{Acknowledgments}

We thank Alella Vinicola, S.A. and Xavier Garcia for their support and interest in this study.

\section{References}

(1) Pourcel, L., Routaboul, J.M., Cheynier, V., Lepiniec, L., \& Debeaujon, I. (2007) Trends Plant Sci. 12, 29-36. doi:10.1016/j. tplants.2006.11.006

(2) Lattanzio, V., Lattanzio, V.M.T., \& Cardinali, A. (2006) in Phytochemistry: Advances in Research, F. Imperato (Ed.), Research Signpost, Kerala, India, pp 23-67

(3) Valentao, P., Guerra, L., Pereira, D.M., \& Andrade, P.B. (2009) in Red Wine and Health, P. O'Byrne (Ed.), Nova Science Publishers, Inc., Hauppauge, NY, pp 53-90

(4) Manach, C., Scalbert, A., Morand, C., Remesy, C., \& Jimenez, L. (2004) Am. J. Clin. Nutr. 79, 727-747

(5) Tsao, R. (2010) Nutrients 2, 1231-1246. doi:10.3390/ nu2121231

(6) Bueno, J.M., Ramos-Escudero, F., Sáez-Plaza, P., Muñoz, A.M., Navas, M.J., \& Asuero, A.G. (2012) Crit. Rev. Anal. Chem. 42, 102-125. doi:10.1080/10408347.2011.632312

(7) Obrenovich, M.E., Nair, N.G., Beyaz, A., Aliev, G., \& Reddy, V.P. (2010) Rejuvination Res. 13, 631-643. doi:10.1089/rej.2010.1043

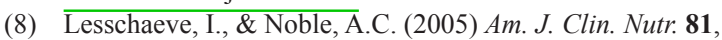
330S-335S
(9) Cardona, F., Andrés-Lacueva, C., Tulipani, S., Tinahones, F.J., \& Queipo-Ortuño, M.I. (2013) J. Nutr. Biochem. 24, 1415-1422. doi:10.1016/j.jnutbio.2013.05.001

(10) Morton, L.W., Caccetta, R.A., Puddey, I.B., \& Croft, K.D. (2000) Clin. Exp. Pharmacol. Physiol. 27, 152-159. doi:10.1046/j.1440-1681.2000.03214.x

(11) Ramos, S. (2007) J. Nutr. Biochem. 18, 427-442. doi:10.1016/j. jnutbio.2006.11.004

(12) Seifried, H.E., Anderson, D.E., Fisher, E.I., \& Milner, J.A. (2007) J. Nutr. Biochem. 18, 567-579. doi:10.1016/j. jnutbio.2006.10.007

(13) Queen, B.L., \& Tollefsbol, T.O. (2010) Curr. Aging Sci. 3, 34-42. doi:10.2174/1874609811003010034

(14) Balsano, C., \& Alisi, A. (2009) Curr. Pharm. Des. 15, 3063-3073. doi:10.2174/138161209789058084

(15) Soory, M. (2009) Infect. Disord.: Drug Targets 9, 400-414

(16) Coppo, E., \& Marchese, A. (2014) Curr. Pharm. Biotechnol. 15, 380-390. doi:10.2174/138920101504140825121142

(17) Saurina, J., \& Sentellas, S. (2015) in Fast Liquid Chromatography-Mass Spectrometry Methods in Food and Environmental Analysis, Ch. 13, O. Núñez (Ed.), Imperial College Press, London, United Kingdom

(18) Saurina, J. (2010) Trends Analyt. Chem. 29, 234-245. doi:10.1016/j.trac.2009.11.008

(19) Rodríguez-Bernaldo de Quirós, A., Lage-Yusty, M.A., \& López-Hernández, J. (2009) Food Res. Int. 42, 1018-1022. doi:10.1016/j.foodres.2009.04.009

(20) Kammerer, D., Claus, A., Carle, R., \& Schieber, A. (2004) J. Agric. Food Chem. 52, 4360-4367. doi:10.1021/ jf049613b

(21) Peña-Neira, A., Hernández, T., García-Vallejo, C., Estrella, I., \& Suarez, J.A. (2000) Eur. Food Res. Technol. 210, 445-448. doi:10.1007/s002170050579

(22) de Villiers, A., Majek, P., Lynen, F., Crouch, A., Lauer, H., \& Sandra, P. (2005) Eur. Food Res. Technol. 221, 520-528. doi:10.1007/s00217-005-1169-5

(23) Jaitz, L., Siegl, K., Eder, R., Rak, G., Abranko, L., Koellensperger, G., \& Hann, S. (2010) Food Chem. 122, 366-372. doi:10.1016/j.foodchem.2010.02.053

(24) Franquet-Griell, H., Checa, A., Nunez, O., Saurina, J., Hernández-Cassou, S., \& Puignou, L. (2012) J. Agric. Food Chem. 60, 8340-8349. doi:10.1021/jf302078j 
(25) Serrano-Lourido, D., Saurina, J., Hernández-Cassou, S., \& Checa, A. (2012) Food Chem. 135, 1425-1431, doi: 10.1016/j. foodchem.2012.06.010

(26) García-Marino, M., Hernández-Hierro, J.M., Santos-Buelga, C., Rivas-Gonzalo, J.C., \& Escribano-Bailón, M.T. (2011) Talanta 85, 2060-2066. doi:10.1016/j.talanta.2011.07.039

(27) Cabrita, M.J., Aires-De-Sousa, J., Da Silva, M.D.R.G., Rei, F., \& Freitas, A.M.C. (2012) Aust. J. Grape Wine Res. 18, 138-146. doi:10.1111/j.1755-0238.2012.00182.x

(28) Www.eigenvector.com/software/solo.htm
(29) Massart, D.L., Vandeginste, B.G.M., Buydens, L.M.C., De Jong, S., Lewi, P.J., \& Smeyers-Verbeke, J. (1997) Handbook of Chemometrics and Qualimetrics: Part A, Elsevier, Amsterdam, The Netherlands

(30) García-Villar, N., Saurina, J., \& Hernández-Cassou, S. (2006) Anal. Chim. Acta 575, 97-105. doi:10.1016/j. aca.2006.05.074

(31) Checa, A., Oliver, R., Hernández-Cassou, S., \& Saurina, J. (2008) Anal. Chim. Acta 616, 85-94. doi:10.1016/j. aca.2008.04.026 